\title{
Shortcomings in addressing attacks on health care
}

\author{
Dilshad Jaff
}

\section{Main text}

The recent review by Carolyn Briody and colleagues "Review of attacks on health care facilities in six conflicts of the past three decades" is thought provoking and timely [1]. Attacks on healthcare, a strong violation of the Geneva conventions, is appropriately getting more attention and the amount of literature is proliferating steadily. I would like to address two limitations of the article by Briody et al.

First, as the authors note, there is no agreement on the definitions of, for example, "attacks" and "facilities" to ascertain accurate estimates. As a physician in the Iraqi health system and later with the International Committee of the Red Cross (ICRC), I directly experienced frequent attacks on health care facilities and learned of others that were not likely to be included in official reports. The estimation of only 12 incidents between March 2003 to December 2011 cannot possibly reflect the reality and it is misleading to report as such. Further, while entities such as Physicians for Human Rights may include reports in local languages there is no systematic process to gather and analyze these reports, further undermining the credibility of estimates [2].

Second, it is essential to acknowledge that the context in which today's attacks occur is fundamentally different from in the past. The infrequent examples of such attacks prior to the end of the cold war is likely due to the fact that states were the primary combatants willing to pay at least some attention to the Geneva conventions. The contemporary attacks described by the authors involved state as well as non-state combatants motivated by religion, ethnicity and sect [3]. Given that the world leaders cannot hold state actors accountable, a call for accountability among non-state actors, while desirable, sounds impractical.

\section{Abbreviation}

ICRC: International Committee of the Red Cross

\author{
Acknowledgements \\ Not applicable. \\ Funding \\ Not applicable.
}

Availability of data and materials

Not applicable.

\section{Author's contribution}

The author read and approved the final manuscript.

\section{Authors' information}

Dilshad Jaff, MD, MPH, is a program coordinator for solutions to complex emergencies with the Gillings School's Research, Innovation and Global Solutions unit, as well as an adjunct assistant professor in the Department of Maternal and Child Health. He also is a Rotary Peace Fellow and holds a Master of Public Health degree from the Gillings School.

Dr. Jaff has more than 17 years' experience in complex humanitarian crises in conflict zones in the Middle East, largely working with the International

Committee of the Red Cross. He has experience in designing, implementing, supervising, and monitoring health projects and programs during and after complex humanitarian emergencies. In addition to his formal studies in medicine and public health, he has studied medical microbiology and has considerable training in conflict resolution.

Ethics approval and consent to participate Not applicable.

\section{Consent for publication}

Not applicable.

\section{Competing interests}

The author declares that he/she has no competing interests

\section{Publisher's Note}

Springer Nature remains neutral with regard to jurisdictional claims in published maps and institutional affiliations.

Received: 5 July 2018 Accepted: 2 December 2018

Published online: 11 December 2018

\section{References}

1. Briody C, Rubenstein L, Roberts L, Penney E, Keenan W, Horbar J. Review of attacks on health care facilities in six conflicts of the past three decades. Confl Heal. 2018;12:19. https://doi.org/10.1186/s13031-018-0152-2.

2. Jaff $D$, Singh $K$, Margolis $L$. Targeting health care in armed conflicts and emergencies: is it underestimated? Med Confl Surviv. 2016;32:1):21-9.

3. Jaff $D$, Violence ML. Armed conflict, and the burden of mental illness in the Middle East and beyond. In: Cambridge scholars PUBLIS; 2017. 